\title{
Combined Effect of Initial Curing Temperature and Crack Width on Chloride Penetration in Reinforced Concrete Beams
}

\author{
Lotfi Elkedrouci ${ }^{1 *}$, Bo Diao ${ }^{1,2}$, Sen Pang ${ }^{1}$, and $Y i \mathrm{Li}^{1}$ \\ ${ }^{1}$ School of Transportation Science and Engineering, Beihang University, Beijing 100083, China \\ ${ }^{2}$ State Laboratory of Subtropical Building Science, South China University of Technology, \\ Guangzhou 510640, China
}

\begin{abstract}
Reinforced concrete (RC) structures are gradually being degraded all over the world, largely due to corrosion of the embedded steel bars caused by an attack of chloride penetration. Initial curing would be regarded as one factor influencing chloride diffusion in concrete in combination with cover cracking that is also of great attention for reinforced structures. In this study, a non-steady state diffusion test of chloride ion involving $\mathrm{RC}$ beam specimens with a water-to-cement ratio of 0.5 , initial curing temperatures of $5^{\circ} \mathrm{C}$ or $20^{\circ} \mathrm{C}$ and three types of crack widths ranging from 0 to $0.2 \mathrm{~mm}$ was performed. Chloride content at $5^{\circ} \mathrm{C}$ or was determined. The results show that the higher chloride content was obtained in condition of crack width large than $0.1 \mathrm{~mm}$ with low initial curing temperature and there are no obvious differences in chloride content when the crack width was not larger than $0.1 \mathrm{~mm}$.
\end{abstract}

\section{Introduction}

A durable reinforced concrete structure must withstand the couple actions of environment and loads over its service life (physical, chemical, mechanical...), as well as various actions such as wind, rain, cold, heat, ambient... while maintaining its aesthetic. Chloride penetration is one of the frequent aggressive agents affecting durability of reinforced concrete structures by corrosion of steels bars, which leads to the deterioration and even collapse of concrete structures [1]. One of the predominant ways that chloride penetrate into concrete structures is diffusion [2], which can be affected by several important factors. During service life, concrete structure may suffer complicated stress conditions of compression or tension leading to inevitable cracks due to the weakness of concrete in tension, which have a deep effect on chloride diffusion [3] and may results in different crack widths distribution within the change of concrete under different external loads, causing an easy way to chloride diffusion [4]. Incursion of chloride ion into concrete leads to break the passive film causing steel corrosion and resulting in cracking and spalling of concrete cover [5], in addition it also leads to decreasing the strength of reinforced

*Corresponding author: chinepekin0@gmail.com 
concrete structures and the structural safety [6]. Obviously, existence of crack has a significant effect on chloride ingress which leads to increase the chloride diffusion [7]. Many researchers have studied chloride diffusion through concrete structures separately without considering the couple effects of an external load and aggressive agent in service environment [8]. The initial curing condition to which concrete is subjected has a significant effect in determining the chloride diffusion rate in concrete [9]. Poor initial curing conditions cause drying of cementitious materials especially at the surface, leading to restrict the hydration at the surface layer as well as the higher porosity and permeability [10]. The lower hydration of cementitious materials may happen in lower curing temperature and accelerated in higher curing temperature [11].

In this study, the combined effects of initial curing temperature and loading crack width on chloride permeation have been experimental investigated. The chloride content was tested and analyzed according to variations of initial curing temperature and loading crack width. The non-steady state accelerated migration test was employed to explore chloride concentration.

\section{Experimental study}

\subsection{Materials and specimens design.}

Two groups, total of 54 reinforced concrete beam specimens were cast for experiment using 42.5 ordinary Portland cement with water/cement ratio 0.5 , where 27 beam specimens for each group. Two reinforcing steel bars of $340 \mathrm{~mm}$ in length and $10 \mathrm{~mm}$ in diameter were placed in tensile area of reinforced concrete beam. Two stainless steel electrodes were employed for electrical migration test measurements. They were attached at the extremities of the steel bars, which were impregnated at a depth of $30 \mathrm{~mm}$ as shown in Fig. 1(a).

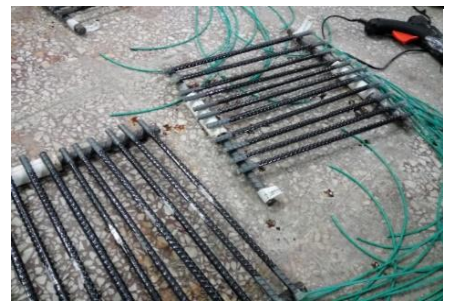

(a)
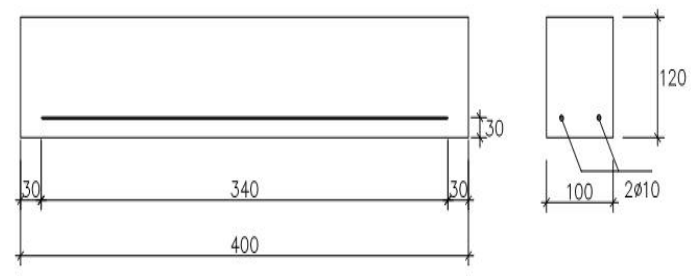

(b)

Fig. 1. Reinforcement bars and geometry size of beam specimen, (a): Steel bars, (b): Geometric sizes of beam specimen.

Reinforced concrete beam specimens were made in factory of prefabrication. The concrete beam specimens were cast inside steel molds, then compacted on a vibrating table. The concrete beam specimens were demolded after $24 \mathrm{~h}$.

\subsection{Curing conditions}

After demolding, two groups of beam specimens were cured in two initial curing temperatures of $5^{\circ} \mathrm{C}$ or $20^{\circ} \mathrm{C}$ for 28 days, respectively. First group of beam specimens was cured in normal temperature of laboratory, which was simply controlled about $20^{\circ} \mathrm{C}$, this normal temperature group was named NT for short. Second group of concrete beam 
specimens was initially cured in a low temperature chamber of $5^{\circ} \mathrm{C}$, this group was named LT for short.

\subsection{Initial cracks by three-point loading}

The chloride contents of three points bending test was experimental investigated by several researchers such as [12]. However, there are no experiments deal with the initial curing temperatures. The concrete beam specimens of $400 \mathrm{~mm}$ length, $100 \mathrm{~mm}$ wide and $120 \mathrm{~mm}$ height here were designed. And flexural cracks were produced by applying three-points loading. As soon as bending crack appeared, unload the beam specimens and crack were closed. Then the crack widths were inspected and photographed by crack width measuring instrument. The different widths of flexural cracks were performed by static three-point loading as illustrated in Fig. 2.

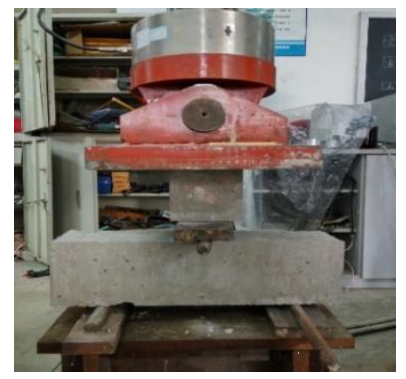

(a)

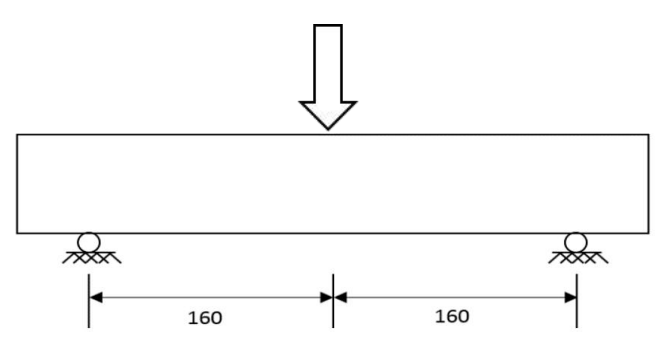

(b)

Fig. 2. Three-points loading of reinforced concrete beam specimen, (a): Photo of three-points loading, (b): Schematic diagram of three-points loading.

According to the crack widths, the beam specimens were classified into three types in this study. First type, crack widths were wider (in the range of $0.1 \mathrm{~mm} \sim 0.2 \mathrm{~mm}$ ) labelled 'W'. Second type, crack widths were narrow (in the range of $0.05 \mathrm{~mm} \sim 0.1 \mathrm{~mm}$ ) labeled ' $N$ '. Third one, as reference, the beam specimen without crack labelled ' 0 '.

\subsection{Accelerated chloride migration test}

In order to explore the effects of initial curing temperature and width of concrete crack on chloride diffusion, a non-steady state accelerated migration test method was employed and developed in our laboratory basing on forcing chloride ion to penetrate through cover using electrical field. The test method is similar to NT BUILD 492 developed by tang [13] which was investigated by many authors [14]. The principle of the test consists of sandwiching concrete beam specimens between two electrolyte compartments. The test was carried out based on bonding a PVC pipe of $60 \mathrm{~mm}$ diameter and $40 \mathrm{~mm}$ high on the cracked surface of the beam specimens) and sealed all the other cracked areas using epoxy resin to guarantee a one-way diffusion. Concrete specimens were submerged in pure water except the area which is covered by the PVC pipe for 3 to 5 days to ensure that concrete is saturated of water. an external electrical potential of $20-30 \mathrm{~V}$ was applied for 24 hours, applied using a steel tablet immersed in chloride solution as a anode and the steel bars as a cathode as shown in Fig. 3. All beam specimens with different crack widths and under different initial curing temperatures were performed the same accelerated migration test. 


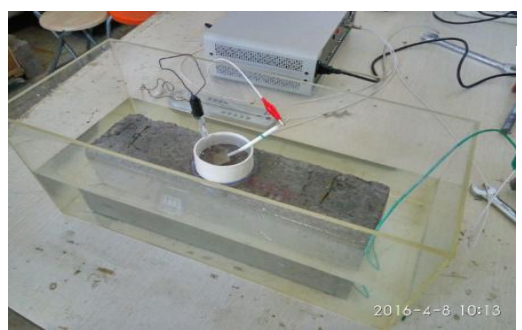

(a)

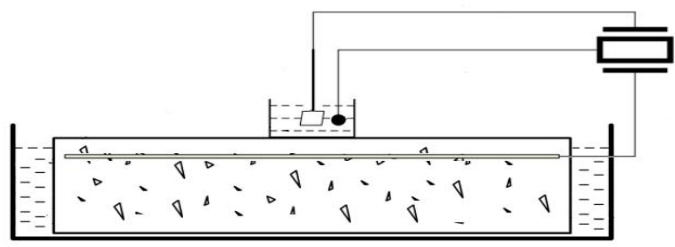

(b)

Fig. 3. Schematic diagram of RCM test of RC beam, (a): RCM test of RC beam specimen, (b): Sketch of RCM test of RC beam specimen.

\subsection{Chloride content test}

After accelerated migration test completed, as shown in Fig. 4, concrete core samples of tensile cracked cover were drilled on one-way diffusion area to evaluate the chloride penetration. The height of core samples was the cover sickness of $30 \mathrm{~mm}$, each core sample was then cut into five circle slices along the depth of cover, the thickness of each circle slice was about $6 \mathrm{~mm}$, then circle slices were grinded into powder to measure the chloride ion concentration. Based on the results, chloride ion content in different depth can be measured.

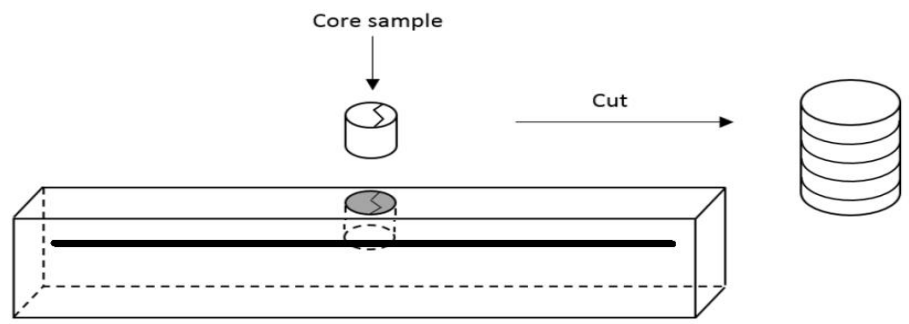

Fig. 4. Schematic diagram of core sample drilling and circle slices sub-cutting.

\section{Results and discussion}

\subsection{Chloride content with crack width}

A remark is to be made concerning the chloride content profiles of concrete beam without crack labelled ' 0 ', with narrow cracks (width $0 \sim 0.1 \mathrm{~mm}$ ) labelled " $\mathrm{N}$ " and with wider cracks (width $0.1 \sim 0.2 \mathrm{~mm}$ ) labelled "W". The variation of chloride content along the depth of concrete cover under two initial curing temperatures with three types of crack widths were shown in Fig. 5.

The variation tendency of chloride content for the three crack widths in both groups of initial curing temperatures was nearly same. High chloride content values were observed near the exposure surface of the beam specimens, then decrease dramatically at $10 \mathrm{~mm}$ of depth. Beyond 10-15 mm of depth reaching the surface of steel bars, the decreasing rate of chloride content is insignificant. For normal initial curing temperature, the chloride content of "W" beam specimens were the largest along the depth for three types of crack width 
beams, which means that the effects of crack width on chloride content was significant. For low initial curing temperature, the effect of crack width on chloride content was also obvious, where the chloride content was the largest when the crack width was larger than $0.1 \mathrm{~mm}$. As shown in Fig. 5, an obvious increase of chloride content was exhibited when the crack width of beam specimens was larger than $0.1 \mathrm{~mm}$ (in the range of $0.1 \sim 0.2 \mathrm{~mm}$ ), no matter the initial curing temperature was lower or not.

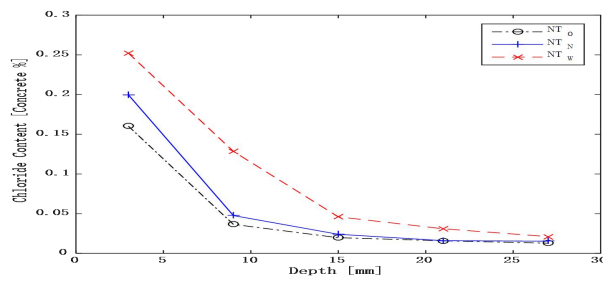

(a)

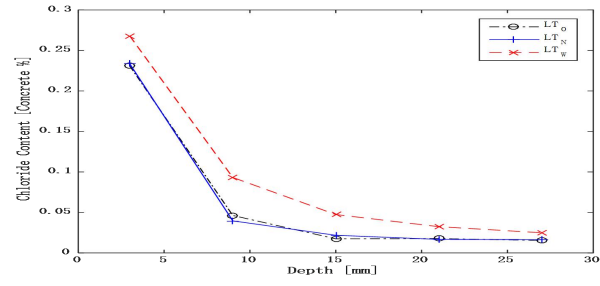

(b)

Fig. 5. Chloride content with depth and crack widths for different initial temperatures, (a): Chloride content with depth and crack for NT, (b): Chloride content with depth and crack for LT

\subsection{Chloride content with initial curing temperature}

Fig. 6 shows the comparison of chloride content with depth at the same crack width for both initial curing temperatures. The chloride content for the three considered crack widths have the same tendency, as the depth increases, the value of chloride content presents no significant difference for both initial curing temperatures. Generally, crack provide the flow paths which leads to the increment of concrete permeability, as a result, aggressive agent or water can easily penetrate into the concrete and to corrode steel bar, leading to performance deterioration [15]. From exposure surface, the chloride content of beams whose crack width is ' $\mathrm{W}$ ' is much larger than that of ' $\mathrm{N}$ ' and ' 0 ' either in NT or LT. Concrete beam specimens with crack width ' 0 ' in both initial curing temperatures have almost the same chloride content values as concrete beam specimens with crack width ' $N$ ', this indicate that crack widths below $0.1 \mathrm{~mm}$ doesn't have a significant effect as much as crack widths in the range of $0.1 \sim 0.2 \mathrm{~mm}$.

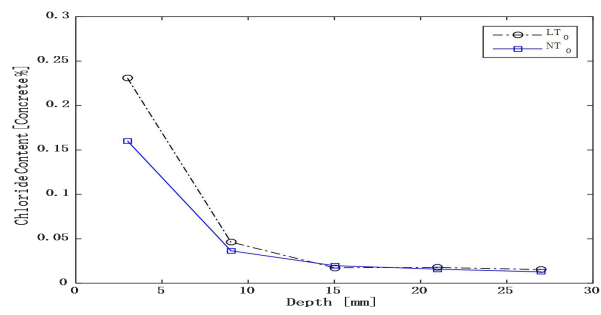

(a)

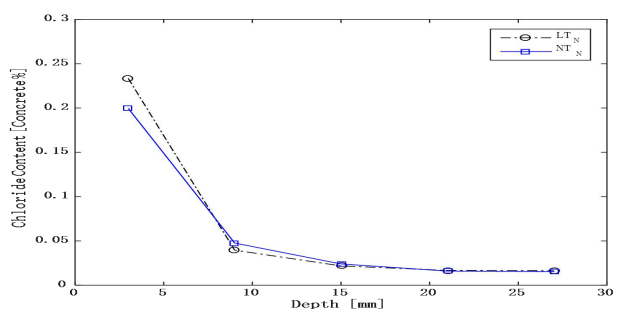

(b) 


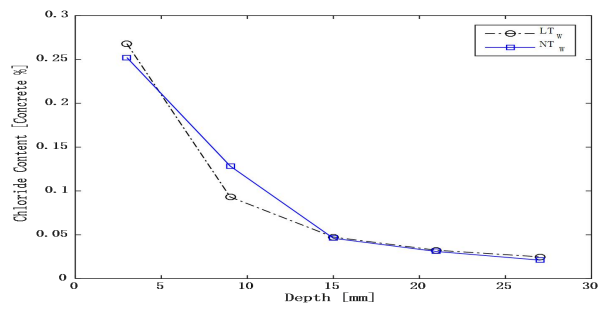

(c)

Fig. 6. Chloride contents along depth for three types of cracks widths and two initial curing temperatures, (a): Chloride content without crack, (b): Chloride content for narrow crack, (c): Chloride content for wide crack.

\subsection{Chloride content at the surface of steel bar}

The chloride content at the surface of steel bar for three types of crack widths and two initial curing temperatures were shown in Fig. 7. As shown in Fig. 7, at steel bar surface, concrete beam specimens with crack width ' $\mathrm{W}$ ' exhibit the highest chloride content in all types of crack widths, which may lead to early corrosion of steel bar [15]. And the chloride contents of the concrete beam specimens curing initially in LT (Lower Temperature $5^{\circ} \mathrm{C}$ ) are higher than that of concrete beam specimens curing initially in NT (Normal Temperature), this can be explained by the fact that initial curing in LT, leads to insufficient hydration process in the active components of the cement [11]. As shown in Fig. 7a, the wider of crack width, the higher chloride content for the same initial curing temperature.

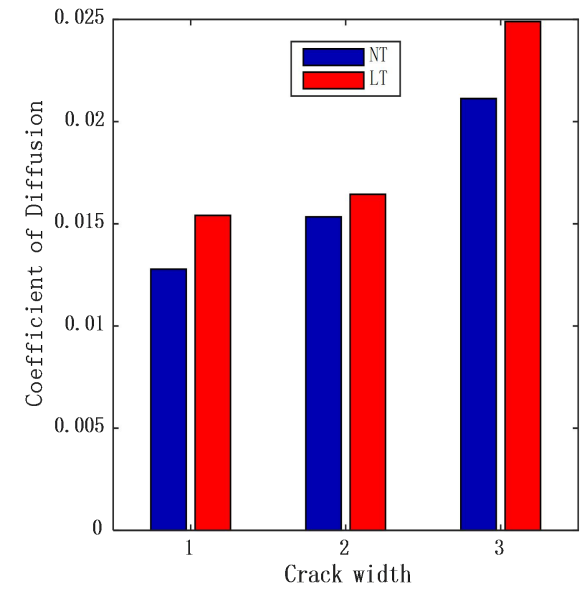

(a)

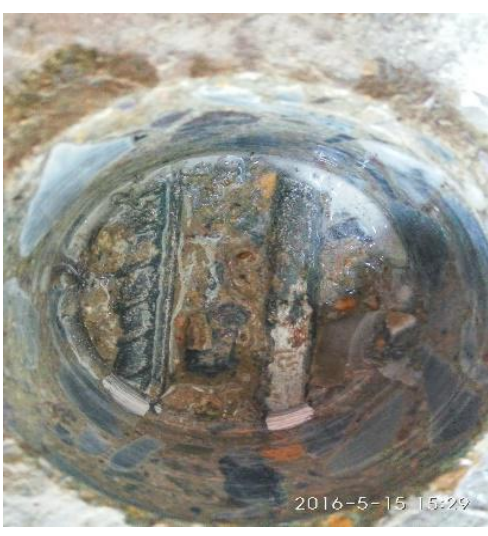

(b)

Fig. 7. Chloride content at the steel bar surface with crack width for LT and NT condition. (a): Chloride content with different crack widths, (b): steel bar surface after drilling core sample.

\section{Conclusions}

Based on the experimental results, the following conclusions may be concluded:

Chloride content of concrete with different cracks is highly dependent on the crack width. High values of chloride content were measured in concrete beam specimens in condition of crack width larger than $0.1 \mathrm{~mm}$ and much less in concrete beam specimens with 
narrow crack (less than $0.1 \mathrm{~mm}$ ) and without crack ('0'mm) for both initial curing temperatures. This shows that wider crack results in high chloride penetration.

The chloride contents of RC beam specimens were almost the same values when the crack width was smaller than $0.1 \mathrm{~mm}$ for both initial curing temperatures. This shows that narrow crack width (less than $0.1 \mathrm{~mm}$ ) have almost the same effect such as concrete beams without crack $(0 \mathrm{~mm})$ on the chloride penetration.

The chloride contents of cracked $\mathrm{RC}$ beam specimens cured initially at $5^{\circ} \mathrm{C}$ were higher than those at $20^{\circ} \mathrm{C}$. This indicates that initial curing temperature have significant impact on chloride penetration of cracked $\mathrm{RC}$ beam specimens.

This work is part of the projects financially supported by the National Natural Science Fund (NSF) of China Grant No. 51678021 and the Fund of State Key Laboratory of Subtropical Building Science (FSKLSBS), South China University of Technology Grant No. 2016ZA03. Authors gratefully acknowledge the funding from the NSF and FSKLSBS.

\section{References}

1. B.H. Oh, S.Y. Jang, cem.con.res, 34 463-480 (2004)

2. L-O. Nilsson, L. Tang (Springer, NL, 289-311 1996)

3. S. Y. Jang, B. S. Kim, B. H. Oh, Cem. Con. Res, 41, 1 (2011)

4. M. Ismail, A. Toumi, R. François, R. Gagné, Cem. Con. Res, 38, 8 (2008)

5. Z. Shao-feng, L. Chun-hua, L. Rong-gui, Pro.E, 24 (2011)

6. C. Lu, W. Jin, R. Liu, Corr. SCI, 53, 4 (2011)

7. H. Wang, W. Jin, C. Lu, Y. Bai, J. Mat. Civ. E, 23, 7 (2011)

8. R.K. Dhir, M.R. Jones, A.E. Elghaly, Cem. Con. Res, 23, 5 (1993)

9. C. Jaegermann, Mat. J, 87, 4 (1990)

10. G. C, Mays (Concrete Press, 2002)

11. J.-K. Kim, S.H. Han, Y.C. Song, Cem. Con. Res, 32 (2002)

12. T. U. Mohammed, N. Otsuki, M. Hisada, T. Shibata, J. Mat. Civ. E, 13, 3 (2001)

13. T. Luping, L.-O. Nilsson, ACI. Mat. J, 89, 49-53 (1993)

14. O. Truc, J.P. Ollivier, M. Carcassès, Cem. Con. Res, 30, 217-226 (2000)

15. K. Wang, D.C. Jansen, S.P. Shah, A. F. KArr, Cem. Con. Res, 27, 3 (1997) 